\title{
Detecting the impact of land cover change on observed rainfall.
}

\author{
Chun X Liang ${ }^{1}$, Floris F. van Ogtrop ${ }^{1}$, R. Willem Vervoort ${ }^{\text {Corresp. } 1}$ \\ ${ }^{1}$ School of Life and Environmental Sciences, Sydney Institute of Agriculture, The University of Sydney, New South Wales, Australia \\ Corresponding Author: R. Willem Vervoort \\ Email address: willem.vervoort@sydney.edu.au
}

Analysis of observational data to pinpoint impact of land cover change on local rainfall is difficult due to multiple environmental factors that cannot be strictly controlled. In this study we use a statistical approach to identify the relationship between removal of tree cover and rainfall with data from best available sources for two large areas in Australia. Gridded rainfall data between 1979 and 2015 was used for the areas, while large scale (exogenous) effects were represented by mean rainfall across a much larger area and climatic indicators, such as Southern Oscillation Index and Indian Ocean Dipole. Both generalised additive modelling and step trend tests were used for the analysis. For a region in south central Queensland, the reported change in tree clearing between 2002 2005 did not result in strong statistically significant precipitation changes. On the other hand, results from a bushfire affected region on the border of New South Wales and Victoria suggests significant changes in the rainfall due to changes in tree cover. This indicates the method works better when an abrupt change in the data can be clearly identified. The results from the step trend test also mainly identified a positive relationship between the tree cover and the rainfall at $p<0.1$ at the NSW/Victoria region. High rainfall variability and possible regrowth could have impacted the results in the Queensland region. 


\title{
Detecting the impact of land cover change on observed rainfall.
}

\author{
Chun X. Liang ${ }^{1}$, Floris F. van Ogtrop ${ }^{1}$, and R. Willem Vervoort ${ }^{1}$ \\ ${ }^{1}$ School of Life and Environmental Sciences, Sydney Institute of Agriculture, The \\ University of Sydney, New South Wales, Australia.
}

Corresponding author:

R. Willem Vervoort ${ }^{1}$

Email address: willem.vervoortesydney.edu.au

9 ABSTRACT

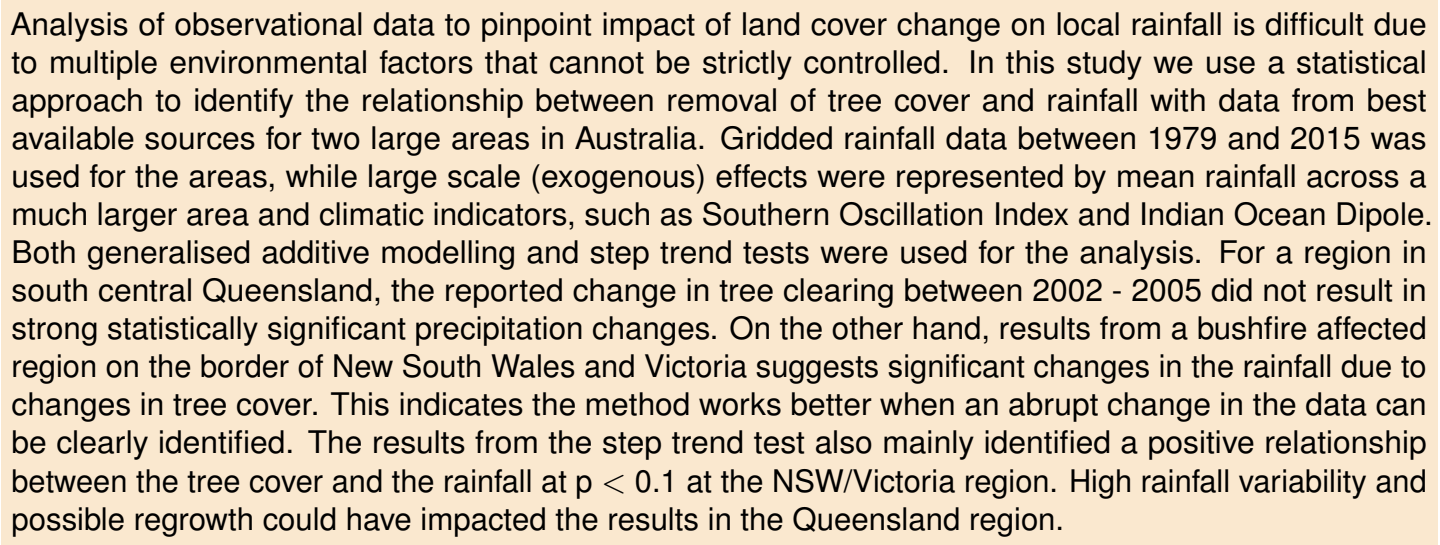
region on the border of New South Wales and Victoria suggests significant changes in the rainfall due to changes in tree cover. This indicates the method works better when an abrupt change in the data can be clearly identified. The results from the step trend test also mainly identified a positive relationship between the tree cover and the rainfall at $p<0.1$ at the NSW/Victoria region. High rainfall variability and possible regrowth could have impacted the results in the Queensland region.

\section{INTRODUCTION}

Land use and land cover changes can lead to changes in the local climate. Empirical and modelling studies have found that cloud types and rainfall are correlated to large scale vegetation cover changes, such as deforestation in the Amazon and in the Sahel (Chagnon \& Bras, 2005; Wang et al., 2009; Pinto et al., 2009; Mei \& Wang, 2010; Kucharski, Zeng \& Kalnay, 2013; Pitman \& Lorenz, 2016) and afforestation in south Israel (Otterman et al., 1990; Ben-Gai et al., 1998). Using airborne measurements in Western Australia, Junkermann et al. (2009) showed a significantly higher level of aerosols over an agricultural area compared to an adjacent area with natural vegetation. They suggested that a modification of aerosol concentrations due to deforestation could have contributed to a reduction of local rainfall, as more, but smaller rain droplets were observed. Nair et al. (2011) reported from the Bunny Fence Experiment in Western Australia that local land use change altered the synoptic west coast trough dynamics and surface roughness, and this resulted in an observed rainfall decrease. Maximum temperatures were also found to be sensitive to land cover change in eastern Australia (McAlpine et al., 2007).

Overall the number of empirical studies analyzing changes to rainfall due to land cover change from observational data is limited. Most of the studies mentioned previously were either model simulations, or comparisons of modelled data with observations. This is because there are some fundamental experimental difficulties in both space (where does evaporated water reappear as rainfall?) and time (how much time does it take for land cover change effects to appear or disappear?). In addition, in many areas across the globe, rainfall variability is related to a complex set of interactions (outlined below), of which land use change might only be a minor component.

Locally, and on a shorter, daily time scale, there are two main sources that generate rainfall: moisture from advective atmospheric transport; and local evapotranspiration (Eltahir \& Bras, 1996; Bosilovich \& Chern, 2006; Dirmeyer, Brubaker \& DelSole, 2009; Gimeno et al., 2010). The local evapotranspiration 
component is the component considered to be affected by land use change (Eltahir \& Bras, 1996). According to Trenberth (1999), the contribution of advective moisture partially depends on the availability of external moisture and atmospheric transport. On the longer time scale, such as monthly and annually, large scale atmospheric dynamics are affected by large scale climate drivers. For example, many studies have reported significant relationships between rainfall in large parts of Australia and the El NiÃ $\pm 0-$ Southern Oscillation (ENSO) (Verdon et al., 2004; Risbey et al., 2009; Speer, Leslie \& Fierro, 2011). In contrast, local ET is determined by local land surface characteristics, which influence local scale atmospheric dynamics and hence the amount of rainfall, including contribution from both main sources.

Although climate drivers demonstrate some capability to predict Australian rainfall, there is still a large amount of unexplained variance. Westra \& Sharma (2010) pointed out that models based on global sea surface temperature anomalies can only predict up to $14.7 \%$ of annual precipitation variance. More generally, some of the remaining variance could be due to land surface processes as suggested in studies predicting local rainfall (e.g. Ma et al., 2011; Zeng et al., 2012; Pitman \& Lorenz, 2016; Saha, Dirmeyer \& Chase, 2016). However, most are based on modelling experiments and few empirical observational studies have been reported. However, Pitman et al. (2004) found a good match between observations and simulated rainfall changes in southwest Western Australia, forced by land cover change. Timbal \& Arblaster (2006) were able to reproduce the rainfall decline in south west Australia by including land cover influence. In addition, local land use change might not be a primary, but is likely to be a secondary cause of rainfall change (Nicholls, 2006).

Therefore, the aim of this study is to use a statistical approach on rainfall data at regional scales to investigate the cause and effect relationship between land cover change and local rainfall, which is demonstrated in many modelling studies. More specifically, we hypothesize that a step change in land cover on the surface will cause a step change in the rainfall. To demonstrate this we study changes in observed rainfall over time at a Queensland and NSW/Victoria location where there are possible step changes in land cover change due to land clearing and bush fires. The methodology uses statistical approaches to identify changes in rainfall, which are subsequently associated with land cover change through spatial comparison.

In this paper, after this section (the introduction), section 2 covers the case study areas and the observed land use change. Section 3 describes the data used in the study in more detail. Section 4 details the statistical methods and the underlying assumptions related to the modelling approach, Section 5 gives the results, which are further discussed in section 6 and finally section 7 offers the conclusions.

\section{STUDY REGIONS AND TREE COVER CHANGE}

In Australia, significant tree cover change has mainly occurred in the north east and south east of the continent, as well as in the southwest of Western Australia. According to the National Dynamic Land Cover Dataset (DLCD) (Lymburner et al., 2010), most of these areas have experienced decreases in the Enhanced Vegetation Index (EVI) post 2000, as derived from satellite data. As an index for vegetation greenness, the decreasing values of EVI indicate lower biomass over time in the tree cover regions. The possible EVI reduction might be due to land clearing, bush fires or drought.

Two regions were selected where significant tree cover change since 2000 was reported. The first region is located in south central Queensland (QLD) partly covering the north of the Murray Darling Basin (MDB) (site 1 in Figure 1). High rates of land clearing have been reported in this region during the early 2000s (Department of Natural Resources and Water, 2007). The second study region is located at the border of New South Wales and Victoria (NSW/VIC), and includes the Snowy Mountain ranges (site 2 in Figure 1). Severe bush fires occurred in this area in early 2003 (see Figure 2). The 2003 bush fires were the largest in the last 60 years (The State Government of Victoria, 2011). Two thirds of Kosciuszko national park was heavily burned and regrowth was suggested to be slow due to drought and cold conditions (ABC News, 2003), and the type of species in this region. However, in the longer term, after an early high transpiration period a recovery of pre-fire evapotranspiration would be expected (Kuczera, 1987). For the purpose of this study, significant tree cover loss has happened in both study areas in the last decade, either permanently or temporarily.

The two regions have different characteristics. The QLD region is partially grassland and subtropical, while the NSW/VIC region is mainly within the temperate zone, under the KÃAlppen classification. According to Australian Bureau of Meteorology (BoM), the NSW/VIC region receives $1000-2000 \mathrm{~mm}$ rainfall annually, which is more than double the annual rainfall in the QLD region. Evapotranspiration is 


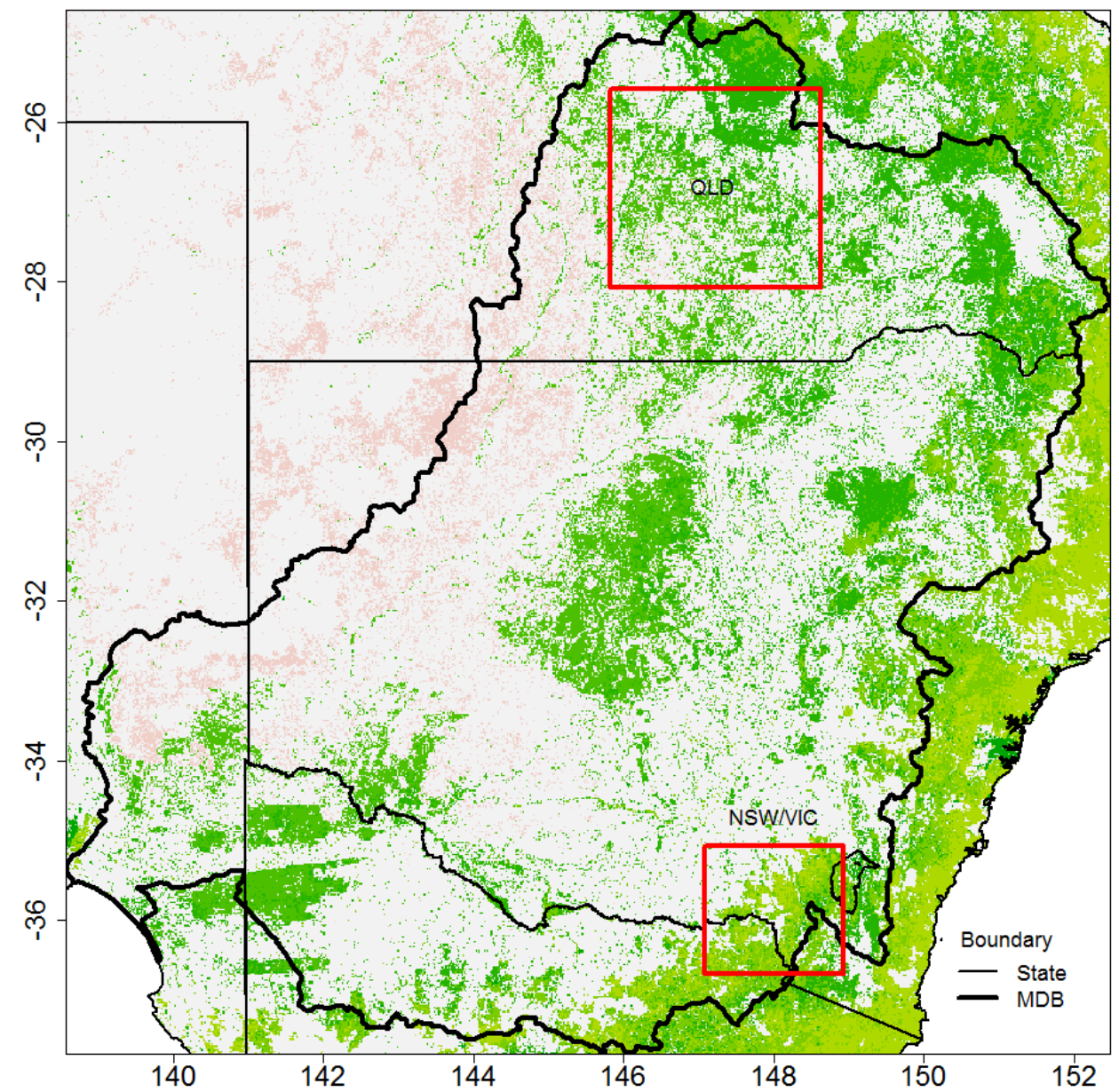

Figure 1. Selected study regions are highlighted by red rectangles in the main map (the red rectangle in the insert indicates the location of the main map). The types of tree cover in 2008 from the DLCD product is shown at the background. In site 1 (the QLD region), the tree cover is mostly sparse. In site 2 (the NSW/VIC region), many areas have open or close forest where the tree cover is denser. 


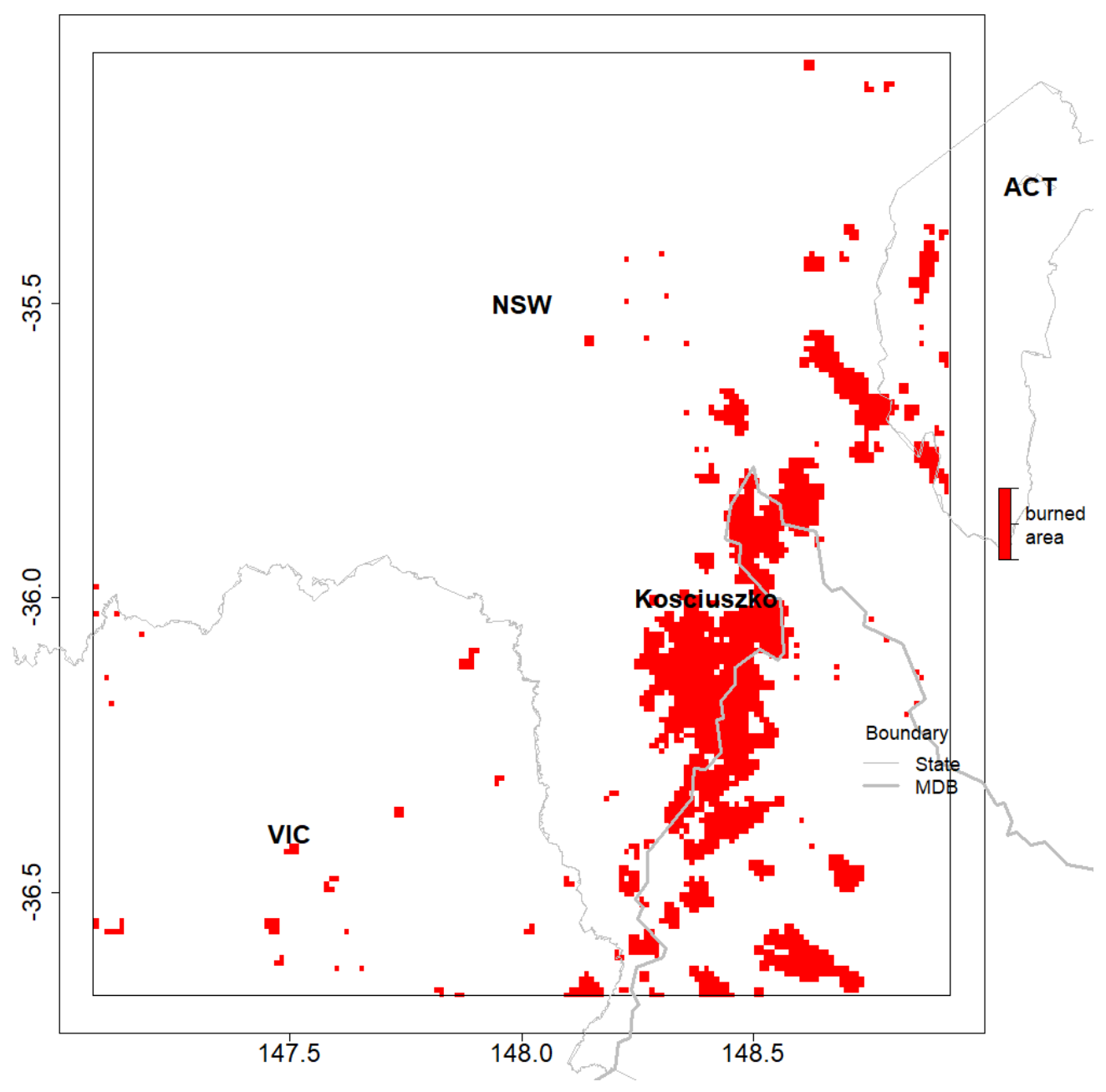

Figure 2. Location of bushfires occurring in January 2003, in and around the NSW/VIC study region, as shown by the red pixels. The map shows the large area in the Kosciuszko national park that has been burned. Some locations in the southwest of the Australian Capital Territory (ACT) have also experienced intensive bushfires. 

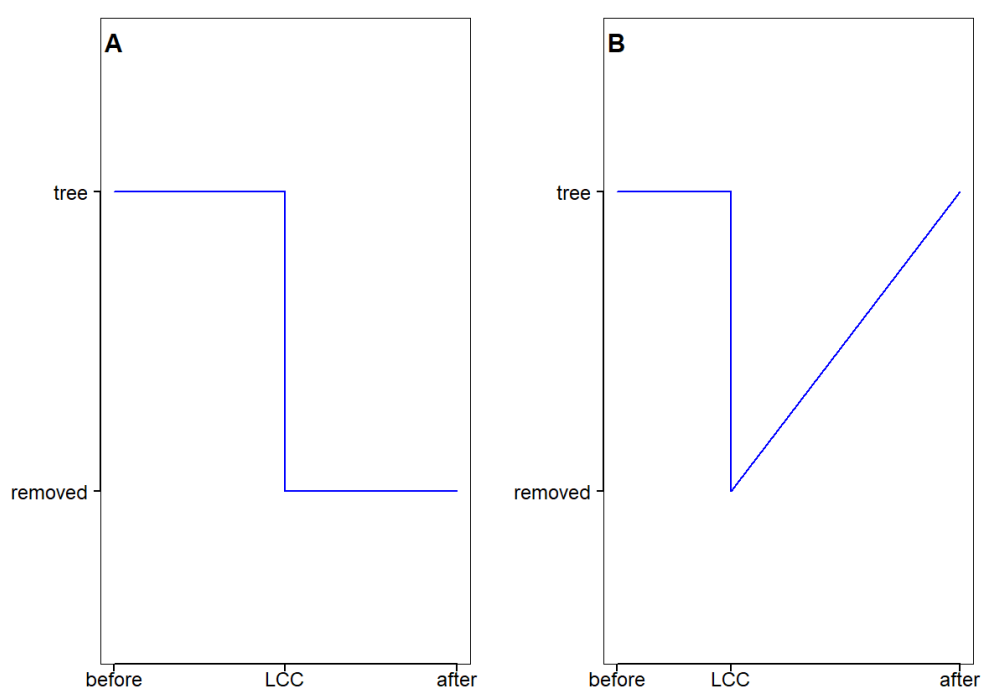

Figure 3. The expected evolution of the land surface after trees have been removed in (A) the QLD region and (B) the NSW/VIC region.

similar in both regions. Marine moisture and orographic effects are likely to be the main contributors to rainfall in the southeast mountain areas of the NSW/VIC region.

The land use and land cover characteristics in the two regions are also different. In the Queensland region, the tree cover is sparse over most of the area. The MODIS satellite tree cover data (discussed in more detail in section 3 ) shows that tree cover in this region is generally below $20 \%$ of total ground area. Grazing is the main activity in this region, with over $90 \%$ of land used by the grazing industry (ABARES, 2010). Our starting assumption is that the main cause of the EVI decline over large part of the region is due to land clearing. Tree cover has been cleared at a massive scale over the last decade, especially during 2002 - 2004. The reports from the Queensland Statewide Land Cover and Trees Study (SLATS) (e.g. Department of Natural Resources and Mines, 2005; Department of Science, Information Technology and Innovation, 2017) were used to investigate the time and location of the land clearing in the QLD region.

The Kosciuszko national park is within the NSW/VIC region. Here tree cover is denser with open or even closed forest (the tree cover distribution is bimodal at $10-20 \%$ and $60-70 \%$ ). The dominant species in the alpine area are Snow Gum (Eucalyptus Pauciflora)and large stand species such as Alpine Ash (Eucalyptus delegatensis) and Mountain Gum (Eucalyptus dalrympleana) in the sub-alpine area. These trees can reach a great height but they take long time to grow. For example, Alpine Ash (Eucalyptus delegatensis) would need about 20 years to mature (40 - $45 \mathrm{~m}$, Buckley et al. (2012)). This region is vulnerable to fires and drought, however land clearing is not a major issue. The MODIS burned area product, MCD45A1 (Roy, Lewis \& Justice, 2002; Roy et al., 2005, 2008), was used to locate bush fires areas in the NSW/VIC region, with a grid resolution of $500 \mathrm{~m}$. MCD45A1 provides monthly burning information on all pixels, which helps to pinpoint an abrupt event.

Due to the difference in nature of the land cover change in the two regions, the post-change vegetation status is hypothesized to be different as well (see Figure 3).

The overall hypothesis is that the effect of 2003 - 2004 land clearings in the QLD region and the 2003 bush fires in the NSW/VIC region cause a step change in the local rainfall. The actual tree cover change during this time at the pixel level was derived from the 15-year MODIS data (discussed below). As the length of the tree cover data is shorter than available rainfall data, earlier land clearing in the QLD region cannot be identified spatially, hence they are excluded from the analysis.

\section{DATA}

Several land surface data sets were used in this study. The main one was the MOD44B product Global Vegetation Continuous Field data set (version 5). This data set provides estimates of percent tree cover 
(percentage of ground surface covered by trees) at a grid resolution of $250 \mathrm{~m}$ (Townshend et al., 2011), which is finer than the earlier mentioned burned product MCD45A1. The data set is available on an annual time interval for the study period of $2000-2015$. The tree cover data was produced from 16day Terra MODIS Land Surface Reflectance data and Land Surface Temperature (Townshend et al., 2011). The National Dynamic Land Cover Dataset (DLCD) (Lymburner et al., 2010) from the Australian Collaborative Land Use Mapping Program (ACLUMP) was used to verify the trend of vegetation cover change calculated from the previous data set. This data set, developed by Geoscience Australia and Australian Bureau of Agricultural and Resource Economics and Sciences (ABARES), is the first nationally consistent and thematically comprehensive land cover reference for Australia. The DLCD is based on the 16-day Enhanced Vegetation Index (EVI), again from the MODIS satellite, between April 2000 and April 2015. It also has a grid resolution of $250 \mathrm{~m}$. The data set provides information on the final land cover types (as in 2015) and estimated trend of EVI statistics (annual mean, maximum and minimum).

The SILO Rainfall product data for Australia was used (Jeffrey et al., 2001) (available online at https://silo.longpaddock.qld.gov.au/)). The data has been projected onto a national $0.05^{\circ}$ by $0.05^{\circ}$ grid (approximately $5 \mathrm{~km}$ by $5 \mathrm{~km}$ ). This gridded data set was generated from station observations using spline interpolation and kriging (Jeffrey et al., 2001). The data has been compared to other gridded products and observed data and is generally of high quality (Tozer, Kiem \& Verdon-Kidd, 2009, 2012). The data is available on a daily and monthly basis from 1889 to current. Here a subset of 36 years (1979 - 2015) was used. The study was conducted on monthly data, as a land cover change effect on annual rainfall might be negligible, but can often be significant in particular months or seasons (e.g. Otterman et al., 1990; Gaertner et al., 2001; Semazzi \& Song, 2001; Oleson et al., 2004; Deo et al., 2009).

Large scale climate drivers are represented by various climatic indices. The Southern Oscillation Index (SOI) is generally regarded as a good predictor of Australian rainfall (Risbey et al., 2009; Chowdhury \& Beecham, 2010; Westra \& Sharma, 2010), but its skill is weaker in some parts of Australia. For example the Southern Annular Mode (SAM) is found to be more important than ENSO in south Western Australia (Meneghini, Simmonds \& Smith, 2007). The testing of the suitability of each index for the regions of interest is described in a later section. The following climate indices were used as candidate predictors for local rainfall.

- Southern Oscillation Index (SOI). The Troup version of the monthly SOI series used in this study was obtained from BoM (available online at http://www.bom.gov.au/climate/ current/soihtm1.shtml).

- Eastern, East Central and Central Tropical Pacific Sea Surface Temperatures (NINO 3, NINO 3.4 and NINO 4). Monthly SST anomalies are available from IRI/LDEO data library and the extended NINO data set is used (available online at http: / / iridl. ldeo. columbia.edu/ SOURCES/.Indices/.nino/.EXTENDED/).

- Pacific Decadal Oscillation (PDO). The Pacific Decadal Oscillation is the leading principal component of monthly SST anomaly in the North Pacific Ocean.. The monthly PDO series was provided by JISAO (Joint Institute for the Study of the Atmosphere and Ocean, University of Washington) (available online at http://jisao.washington. edu/pdo/PDO. latest).

- Indian Ocean Dipole (IOD). The Indian Ocean dipole is commonly measured by the difference between SST anomaly in the western $\left(50-70^{\circ} \mathrm{E}\right.$ and $\left.10^{\circ} \mathrm{S}-10^{\circ} \mathrm{N}\right)$ and eastern $\left(90-110^{\circ} \mathrm{E}\right.$ and 0 $-10^{\circ} \mathrm{S}$ ) equatorial India Ocean (Saji et al., 1999). Monthly IOD was obtained from JAMSTEC (the Japan Agency for Marine-Earth Science and Technology) (available online at http://www . jamstec.go.jp/frcgc/research/dl/iod/DATA/dmi.monthly.txt).

\section{STATISTICAL METHOD}

As an initial analysis a simple boxplot and t-test is used to analyse whether there is a significant change in tree cover in time, and before and after the suspected change in the regions.

To assess the actual causal relationship between the tree cover and the rainfall a flexible regression model is applied (discussed in detail below). A step change is not directly obvious in the time series of the rainfall anomalies (Figure 4) for both regions, even though the data is deseasonalised and detrended. 


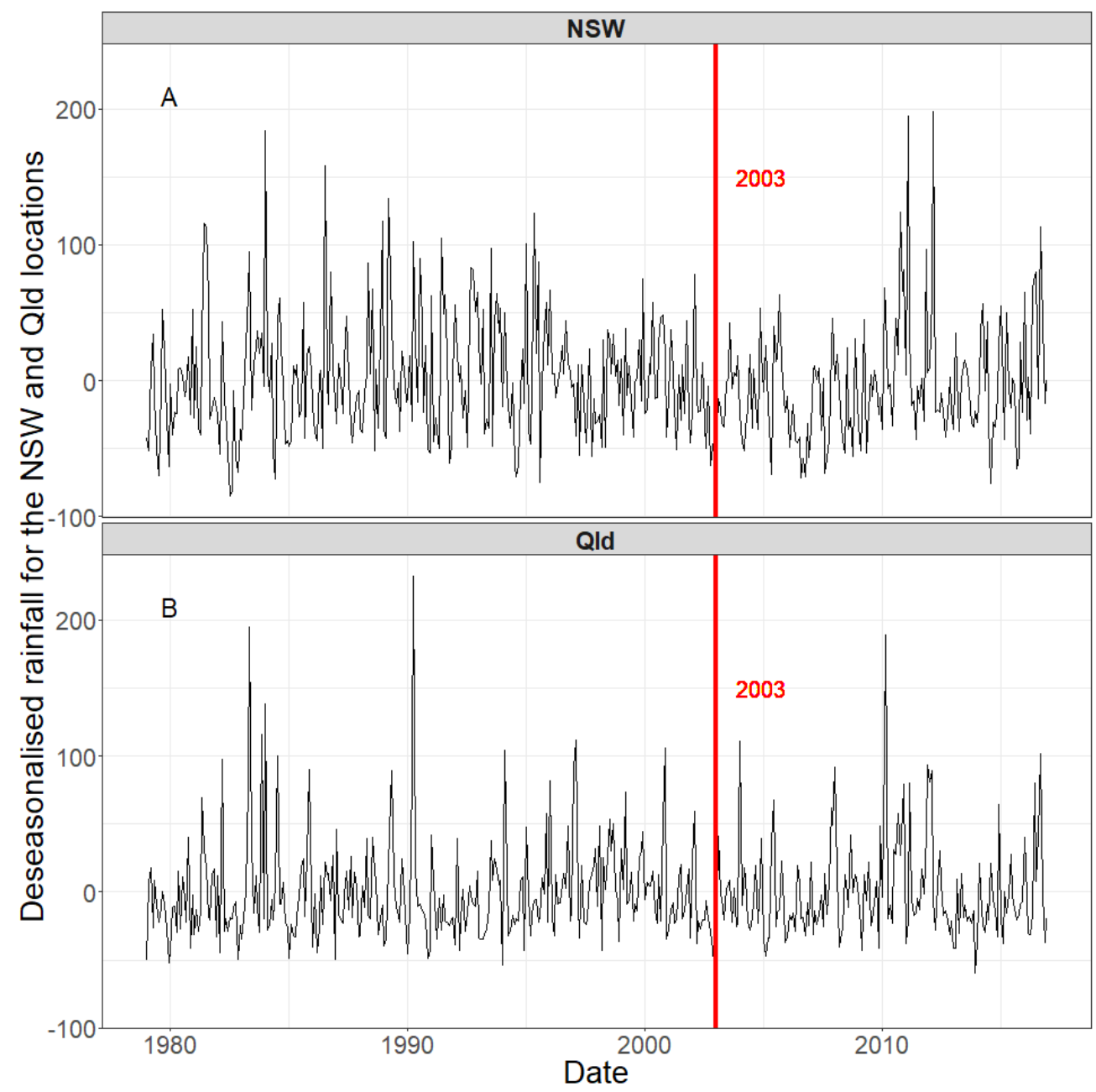

Figure 4. The deseasonalised and detrended rainfall over the 30 years period in (a) the QLD region and (b) the NSW/VIC region. The vertical red lines indicate the year of 2003, in which the studied land cover changes occurred. A change in the time series data is not obvious before and after the land cover changes.

In this study we apply different statistical methods to analyse the effect of tree cover change on rainfall. Both methods make use of a regression model to remove year-on-year variability in rainfall to strengthen the tree cover change signal.

In the first method, the tree cover change is implemented as a factor variable in the regression model, and the significance of this variable is tested. In the second method, a rank sum test (step trend test), is applied to the regression model residuals after effects of other major factors were removed. This assumes that after removal of all climate, long term linear trend and seasonal variation, the vegetation cover change is the only factor explaining the non-random pattern in the rainfall residuals.

\subsection{Regression model}

As highlighted in the introduction, the Australian climate is influenced by sea surface temperatures in the tropical Pacific and Indian Oceans, as well as pressure systems in the Southern Ocean (BoM, 2012). Risbey et al. (2009) compared five large-scale drivers, including ENSO (measured by SOI and the Tropical Pacific Sea surface temperatures (SSTs)), IOD, SAM, MJO (Madden-Julian oscillation) and blocking, in relation to Australian rainfall variability. The MJO is a large scale eastward-propagating wave-like disturbance located around equatorial latitudes (Risbey et al., 2009). They identified SOI as the most important index among all climate indices tested for broad parts of Australia (including QLD and NSW/VIC) in almost any season. In this study, four climate indices were selected from the main climatic indicators (see section Data) and used as the explanatory variables in the model for each study 
region. A further complicating factor is the influence of the "millenium drought" over the study period and in particular the change to wet conditions in 2010 - 2011 (Dijk \& Viney, 2013). Therefore, the spatially averaged monthly rainfall in the Murray Darling Basin (MDB, downloaded from the Bureau of Meteorology) was used to explain the year-on-year variation in the rainfall in the regions. Since both regions at least partly overlap with the MDB, the average rainfall for the entire basin was assumed to be a useful explaining variable.

Correlations between rainfall and each climate index were analysed. Rainfall in each study region was first deseasonalised and detrended using the seasonal decomposition function ds in the package deseasonalise in R (R Core Team, 2018). Using detrended data gives a better indication of the underlying correlation by removing the underlying correlation in the data (Smith \& Timbal, 2012). The cross-correlations between the deseasonalised and detrended rainfall and the climatic indices were tested, and the strongests indicators at lag 0 were identified for the model. Because the PDO describes the multidecadal SST with lower frequency (MacDonald \& Case, 2005; Zanchettin et al., 2008; Kamruzzaman, Beecham \& Metcalfe, 2011), instead of 37-year rainfall data, a longer period (115 years, from 1900 to 2015) was used to estimate the correlation with PDO, up to lag 24 . For the other indices, the 37-year data was used.

Rainfall in Australia shows strong seasonal patterns (Holper, 2011; Australian Bureau of Statistics, 2012). As a result a seasonal component of rainfall has a periodic pattern which should be included in the model. In addition, long term trends in the regional rainfall in some parts of Australia are significant (Hughes, 2003; Gallant, Hennessy \& Risbey, 2007; Chowdhury \& Beecham, 2010). The presence of long term trends can be confused with the outcome of a step change in rainfall. As a result a linear trend term was implemented in the model to remove any long term effects.

We assumed all the factors are additive smooth components in determining rainfall following Kamruzzaman, Beecham \& Metcalfe (2011). In this case, the rainfall model is a generalised additive model (GAM) (Hastie \& Tibshirani, 1986) with a log link function $g()$ and assuming the residuals are gamma distributed. We used the shrinkage version of the cubic regression splines (Wood, 2011) as smooth function. All splines were limited to 3 knots in flexibility (Wood, 2011), to reduce the risk of overfitting.

$$
\begin{aligned}
g\left(E\left(\mathbf{R}_{r}\right)\right)= & \beta_{0}+s_{1}\left(\mathbf{M D B}_{\text {monthlyRain }}\right)+s_{2}(\mathbf{S O I})+s_{3}(\mathbf{I O D})+ \\
& s_{4}(\text { Nino3.4 })+s_{5}(\text { Nino4 })+s_{6}(\text { PDO })+ \\
& \left.s_{7} \text { (Season }\right)+\beta_{1} \text { Trend }+\varepsilon_{r}
\end{aligned}
$$

The bold letters represent the time series vectors. The region is indicated by $r$, while $\beta_{u}\left({ }_{u}=0,1\right)$ are the fitted coefficients in the model. $s_{v}(v=1,2,3, \ldots)$ are the smooth penalized cubic regression spline functions on the climatic indices and the season. $\mathrm{MDB}_{\text {monthlyRain }}$ is the spatially averaged monthly rainfall across the Murray Darling Basin.

The variable Trend $=1,2,3 \ldots \mathrm{n}$, where $\mathrm{n}$ is the total number of months in the time series is the possible long term trend in the data, while Season is the seasonal component. The climatic terms are also modelled with smooth functions as the effect of large scale drivers on Australian rainfall can be seasonal (Murphy \& Timbal, 2008; Schepen, Wang \& Robertson, 2012).

\subsection{Tree cover change as factor variable}

One of the main difficulties in empirical observation studies related to the effect of land cover change on rainfall is the lack of continuous monitoring of land surface variables. Moreover, no specific variable can possibly be defined that can clearly represent the land surface process. Given the lack of a full picture of the land surface process, a factor variable was used in the regression model to represent the abrupt land surface change (see Equation (1)). The change could be a result of either land clearing or bush fires as long as it is permanent or takes a long time to recover. As indicated we approached the problem in two different models ways.

In the first method, the tree cover change was used as a predictor in the regression model, represented by a factor variable $\mathbf{L C}$. The significance of the coefficient of $\mathbf{L C}$, denoted as $\beta_{5}^{\prime}$ in Equation (1), can be determined by a ratio test.

$$
\mathrm{LC}=\left\{\begin{array}{l}
\text { Trees } \\
\text { Removed }
\end{array}\right.
$$


Table 1. Example of ranking rainfall residuals

\begin{tabular}{rrr}
\hline Year & Rainfall residuals & Rank $R_{1 k}^{\prime}$ \\
\hline 1998 & -0.3 & 6 \\
1999 & -60.9 & 2 \\
2000 & -16.1 & 4 \\
2001 & -71.7 & 1 \\
2002 & 111.1 & 7 \\
2005 & -7.2 & 5 \\
2006 & -60.5 & 3 \\
\hline
\end{tabular}

Therefore in both regions, land cover is "trees" for the period before land cover change and "removed" for the period after the change. Here we simply assumed that vegetation cover change has occurred on every pixel. The remaining term $\varepsilon_{r}$ is the amount of rainfall that is attributed to other unspecified factors and random errors. Hence the regression model becomes

$$
\begin{aligned}
g\left(E\left(\mathbf{R}_{r}\right)\right)= & \beta_{0}^{\prime}+s_{1}^{\prime}\left(\mathbf{M D B}_{\text {monthlyRain }}\right)+ \\
& s_{2}^{\prime}(\mathbf{S O I})+s_{3}^{\prime}(\mathbf{I O D})+ \\
& s_{4}^{\prime}(\mathbf{N i n o 3 . 4})+s_{5}^{\prime}(\mathbf{N i n o 4})+s_{6}^{\prime} \mathbf{P D O}+s_{7}^{\prime} \text { Season }+ \\
& \beta_{1}^{\prime} \text { Trend }+\beta_{2}^{\prime} \mathbf{L} \mathbf{C}+\boldsymbol{\varepsilon}^{\prime}{ }_{r}
\end{aligned}
$$

One of the difficulties is to point an exact time to the changes in the vegetation cover in the two regions. In the QLD region, no exact time can be assigned to the land clearing. According to the SLATS reports, the most substantial clearing occurred between $2003-2004$. However, the information on the change in type of land cover during the time period is missing. Therefore, four scenarios were initially tested in the analysis, however there was no real difference between these scenarios. In the NSW/VIC region, severe bush fires were reported in early January 2003. Hence the "tree" cover state was up to December 2002 then it was changed to "removed" state from January 2003. As a starting date, the regression model was run from 1979 for both regions.

\subsection{Step trend test}

To support the regression analysis, a Mann-Whitney Rank-Sum step trend test was used to detect changes in rainfall as a result of vegetation cover change. This specific nonparametric statistical test was modified from the Mann-Whitney U test by Hirsch \& Gilroy (1985) and can identify a step change in data which is cross-correlated. In this case, this is important as the gridded rainfall dataset has a high spatial correlation between neighbouring pixels. The advantages of using the Rank-Sum test are: (1) it does not depend on assumptions of the data distribution; (2) it is not restricted to datasets with no missing data; (3) it is robust and not as easily influenced by outliers and negative numbers (Hirsch \& Gilroy, 1985). However, the test has less power than parametric tests. As a nonparametric rank-based test, it depends on the ranks of the data.

The rainfall residuals from the regression model in Equation (3) were used. The assumption is that the regression model deseasonalises and detrends the rainfall data (Hirsch \& Gilroy, 1985), amplifying the local landuse effects. For each month, rainfall residuals of each year were ranked in an ascending order. The ranking of January rainfall in a sample pixel $\mathrm{k}$ in QLD is illustrated in Table 1.

The before and after period in the data formed two groups of samples. The split point of the two periods was based on the timing of the vegetation cover changes. In the QLD region, changes occurred anytime during 2003 and 2004. In contrast to the previous method, the time period covering the land cover change was excluded, as the nonparametric test allows missing data and the power of the test is greater if data of the change period is ignored (Hirsch \& Gilroy, 1985). As a result, the post change period was 2005 - 2015 for the Queensland location.

In the case of NSW/VIC, the bushfires broke out in early January 2003. The change was within a relatively short period of the year. Therefore the post change period in this region still started in January 2003. The pre change period was set to five years $(1998$ - 2002) in both regions. 
The rank of rainfall in month $\mathrm{j}$ year $\mathrm{i}$ in pixel $\mathrm{k}$ is denoted as $R_{i j k}^{\prime}$. The sum of ranks of rainfall in month $\mathrm{j}$ in pixel $\mathrm{k}$ before the known intervention is:

$$
W_{j k}=\sum_{i=1}^{n_{1}} R_{i j k}^{\prime}
$$

$n_{1}$ is the number of years before the land cover change. The expected value of $W_{j k}$ is

$$
\mu_{w}=n_{1}\left(n_{1}+n_{2}+1\right) / 2
$$

$n_{2}$ is the number of years after the change. Hence the expected value of the rank sum before the intervention is the same for all months and all pixels. The sum of ranks for the whole time period is fixed, as $\left(n_{1}+n_{2}\right)\left(n_{1}+n_{2}+1\right) / 2$. In this study, since there are only two groups (before and after), knowing the rank-sum of one group is the same as knowing the rank-sum of the other group. If the rainfall data is temporally and spatially independent, the variance of $W_{j k}$ is

$$
\sigma_{w}^{2}=n_{1} \cdot n_{2}\left(n_{1}+n_{2}+1\right) / m
$$

where $\mathrm{m}$ is the number of months which is 12 in the case of a full year.

Here the deseasonalised and detrended data shows little autocorrelation in time, but possesses strong cross correlation between neighbouring pixels, i.e. $R>0.99$.

The sum of $W_{j k}$ for a block of $n s$ pixels over the whole year, $\sum_{j=1}^{12} \sum_{k=1}^{n s} W_{j k}$, has mean

$$
E\left(\sum_{j=1}^{12} \sum_{k=1}^{n s} W_{j k}\right)=12 \cdot n s \cdot \mu_{W}
$$

and variance

$$
\operatorname{Var}\left(\sum_{j=1}^{12} \sum_{k=1}^{n s} W_{j k}\right)=\sum_{j=1}^{12} \sum_{k=1}^{n s} \sum_{h=1}^{n s} C\left(W_{j k}, W_{j h}\right) .
$$

$C\left(W_{j k}, W_{j h}\right)$ is the covariance of the $\mathrm{W}$ statistics between pixel $\mathrm{k}$ and pixel $\mathrm{h}$ in month $\mathrm{j}$. When $k=h$, $C\left(W_{j k}, W_{j h}\right)=\sigma_{w}^{2}$. When $k \neq h$,

$$
C\left(W_{j k}, W_{j h}\right)=\sigma_{w}^{2} r\left(R_{k}, R_{h}\right)
$$

where $r\left(R_{k}, R_{h}\right)$ is the product moment correlation coefficient of the concurrent ranks in pixel $\mathrm{k}$ and $\mathrm{h}$. Here $r$ is calculated on the full time series in each pixel. In the analysis, the test was applied to a square block of four pixels each time. As argued by Hirsch \& Gilroy (1985), $n s=4$ is the most optimal solution to balance the cost and the gain in the test power.

The statistic of the step trend test is then defined as

$$
Z^{\prime}=\frac{\sum_{j=1}^{12} \sum_{k=1}^{n s} W_{j k}-12 \cdot n s \cdot \mu_{w}}{\sqrt{\operatorname{Var}\left(\sum_{j=1}^{12} \sum_{k=1}^{n s} W_{j k}\right)}} .
$$

The above statistic is written for a 12 month period. By changing the value 12 , it can also be used to test seasonal rainfall change or for other customized periods.

The null hypothesis $\left(H_{0}\right)$ in this study is that there was no change in rainfall due to land surface intervention. The results of the step trend test can be interpreted according to the sign of the Z' score (see Table 2, Chapter 23, P887 (Hipel \& McLeod, 1994)), and is normally distributed similar to the standard normal statistics $\mathrm{Z}$. 
Table 2. The interpretation of Z' score in the step trend test

$Z^{\prime}>0$ and rainfall decreases after change
$Z^{\prime}<0$ and rainfall increases post change
$Z^{\prime}=0$ and rainfall does not change
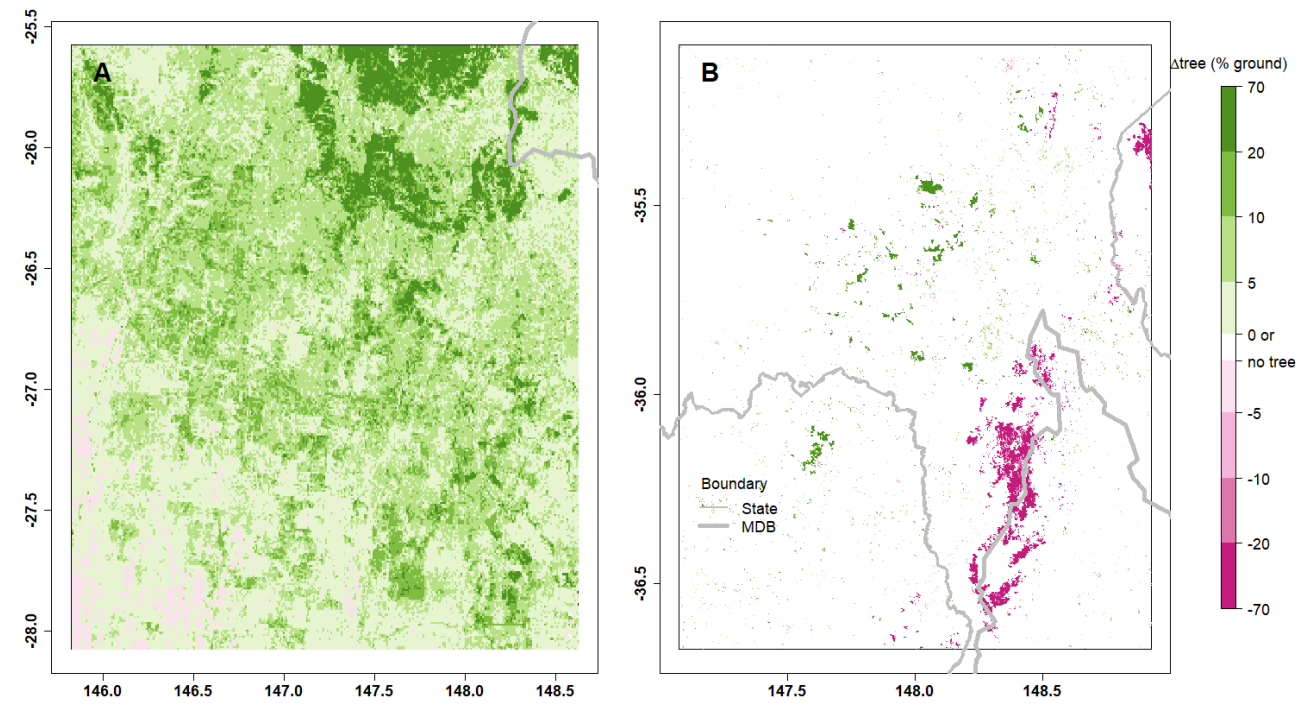

Figure 5. The maps show significant changes in tree cover identified from the MOD44B data between 2003 and 2015 in the Qld region (A) and the NSW/VIC region (B). The amount of change was calculated as the difference in tree cover before and after the specified land cover intervention and it is shown as the percentage of the ground area. Green colour indicates an increase in tree cover, while red colour indicates a decrease in tree cover.

As part of the analysis, the "field significance" of the Z' score test was considered to improve the interpretion of the step change at regional scales from multiple local tests (Wilks, 2006; Westra, Alexander \& Zwiers, 2013). Here, the bootstrapping resampling method from Westra, Alexander \& Zwiers (2013) was used to evaluate the field significance. This means the spatial structure of the pixels was maintained, but the order of the years and months was changed by random resampling. For each resampling, the test statistic identifies the percentage of the pixels with a significant positive or negative step change for the step trend test. The test statistics on 1000 resampled replicates were used to develop the distribution of these percentage values.

\section{RESULTS}

\subsection{Tree cover change}

The pixels, where the tree cover change based on the MOD44B data was significant $(p \leq 0.05)$ in each study region, are shown in Figure 5 for the NSW/VIC region (left panel) and the QLD region (right panel). In the QLD region there actually has generally been an increase in tree cover after the clearing of native vegetation stopped. In the NSW/VIC region, much of the tree loss between 2002 and 2003 was concentrated in the Snowy Mountains close to the border of NSW and VIC, which is also evident in the figure. Tree cover loss occurred in large parts of the QLD region between 2002 and 2005, but this tree loss was spatially less concentrated. 


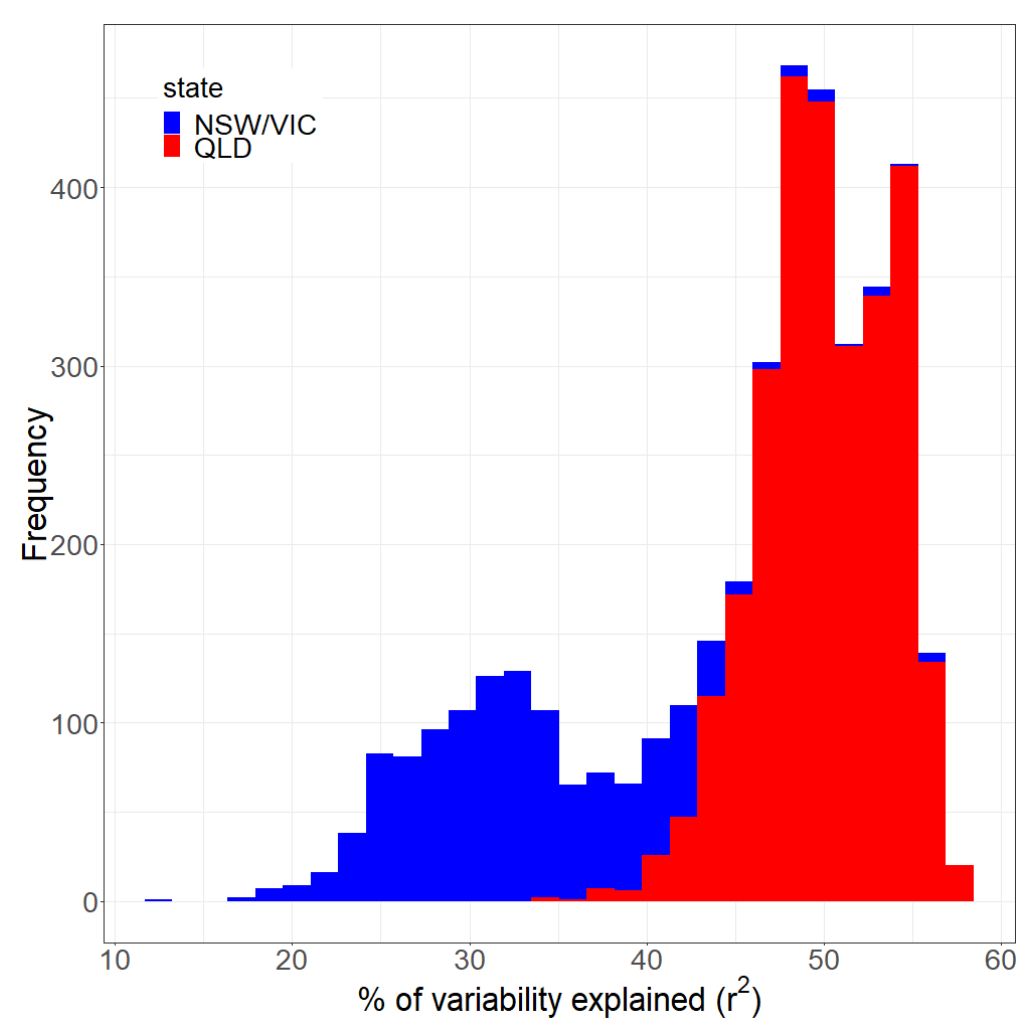

Figure 6. The distribution of the variance explained (adjusted $r^{2}$ ) by the full regression model

\subsection{Regression Model}

The correlation between the climatic indices and rainfall in the regions (See the supplementary material with this paper) indicated that for both regions the PDO had the weakest correlations, and this factor was therefore dropped as a predictor. Although some indices are serially correlated with rainfall up to several months, the lag zero events have the greatest correlation coefficients. Furthermore, using multiple climatic index series was generally found most useful in rainfall prediction (e.g. Risbey et al., 2009; Kamruzzaman, Beecham \& Metcalfe, 2011).

Generally the regression model only explains a limited amount of the rainfall variability (Figure 6). The model in Equation (3) accounts for an average around 33\% of the variation in the NSW/VIC region and about 50\% of the variation in the QLD region as indicated by the adjusted $r^{2}$. The adjusted $r^{2}$ is the coefficient of determination, a measurement of the amount of variability predicted by the model adjusting for the number of explanatory terms.

In terms of predictors of the local rainfall in the model, logically, the average rainfall across the larger Murray Darling Basin is highly significant. This confirms that this variable is a good reflection of the year on year variability in the rainfall. The model also confirms the importance of the climate drivers and the seasonality in Australian rainfall, as many of these variables were significant. Even at the grid level, the seasons and several of the climatic indices were significant $(p \leq 0.05)$ everywhere in both regions. The climate drivers (at lag zero) accounted, on average, for $6.5 \%$ of the rainfall variability in both the QLD region and the NSW/VIC region (see Figure 7 for the distribution of adjusted $r^{2}$ in these two regions). These figures are within the upper bound of seasonal rainfall predictability by a SST anomaly field reported by Westra \& Sharma (2010).

There were generally no statistically significant long term trends in both regions. However, the trend term was kept in the regression model to ensure the detection of step change was not due to a possible long term trend (even if this was not significant).

The land cover variable in the model (Equation (3)) aims to identify a step change in the rainfall before and after the observed change in land cover. The variable was mainly significant $(p \leq 0.05)$ for the rainfall estimates in some areas in NSW/VIC, as shown in Figure 8 (B). However, the number of pixels where the landcover variable was significant was much greater in NSW/VIC compared to the number 


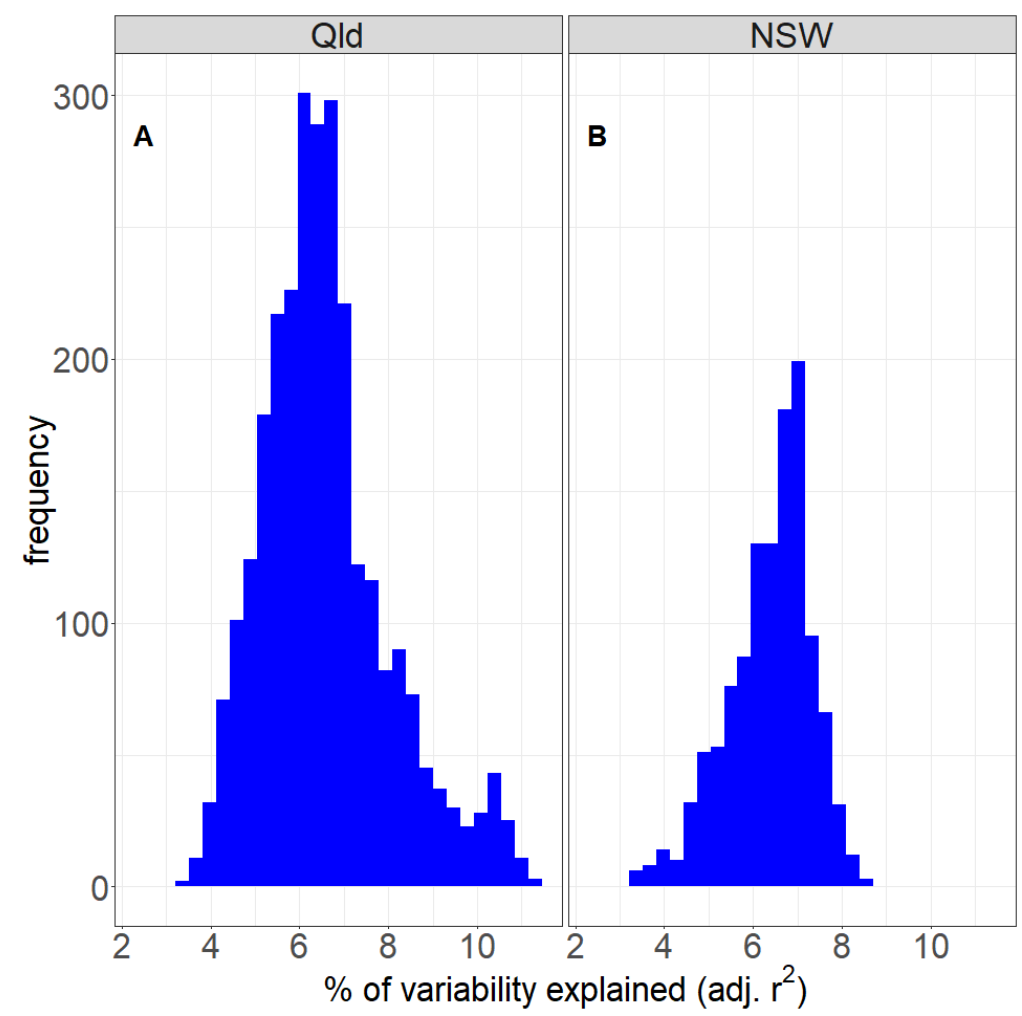

Figure 7. The performance of the regression model if rainfall is only modelled by the climate drivers. It shows the percentage of rainfall variability that can be explained by the climate drivers for the Qld (A) and NSW/VIC (B) region
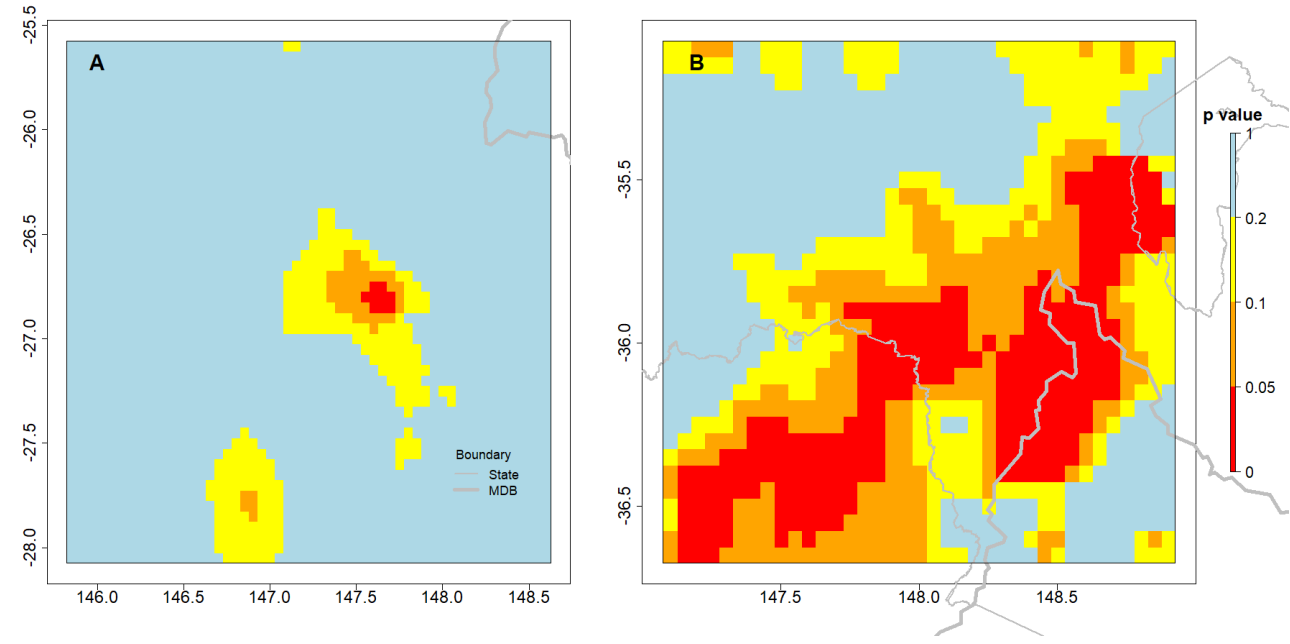

Figure 8. The spatial distribution of significance of land cover step change variable in the GAM model predicting changes in rainfall in the both regions, the Qld region (A) and the NSW/VIC region (B). The outlines of relevant Australian states and the Murray Darling Basin are indicated in grey. The p-value reported is for the land cover variable in the model. 


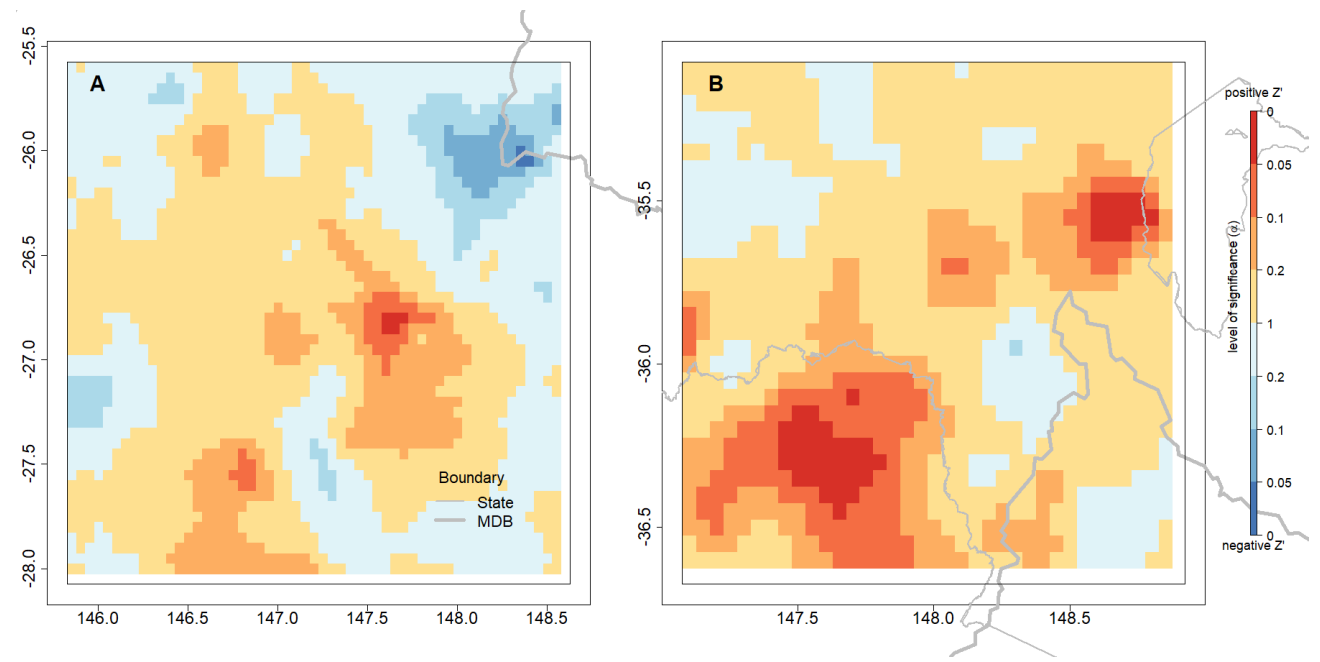

Figure 9. Spatial distribution of the step trend test Z' statistics in the two study sites, the QLD region (A) and the NSW/VIC region (B). Warm colours (yellow, orange and red) are for positive Z' values which indicate decreasing rainfall trend due to the land surface change. Cold colours (light blue to blue) are for negative Z' values which indicate increasing rainfall trend. The deeper the colour, the more significant the statistic.

in the QLD region (Figure $8(\mathrm{~A})$ ). There was also some relationship between the areas of bushfires in Figure 2. Only a very small area with a significant step change due to the land cover changes was found in rainfall in the QLD region (A)

More generally, the model for NSW/VIC suggests that the land cover variable has a positive impact on rainfall in both regions. The fitted coefficients for the Land cover change variable were consistently positive for the "tree" part of the series. It implies that rainfall was higher when the surface was covered by trees.

\subsection{Stronger step trend in NSW/VIC compared to QLD}

In both regions there are areas of positive $Z$ ' values which imply a decrease in rainfall (Figure 9), but this is stronger in the NSW/VIC area (B) than in the QLD area (A). Qualitatively the locations where changes in tree cover occurred in the NSW/VIC area (Figure 5 (B)) seem to agree with the patterns in the Z' scores. However, a direct relationship would not necesssarily be expected as movement of air masses could mean that actual changes of rainfall are observed close by, but not necessarily exactly at areas with changes of landcover. For the QLD region (A) there are only a few significant Z' scores which matches the earlier significance in the landcover variable in the full regresion. In the QLD region, only $0.2 \%$ of the pixels obtained a positive Z' score with $\mathrm{p}<0.1$. In the NSW/VIC region (B) $3.7 \%$ of pixels have a positive $\mathrm{Z}$ ' score with $\mathrm{p}<0.1$. In general it is only a small proportion of both study regions.

The rainfall regression residuals without the landcover variable for the two regions (before-change since 1979 and after-change) were also compared using a simple t-test. The mean rainfall residuals were significantly different $(p<0.05)$ between the "before" and "after" periods in both regions. For the Queensland locations, the mean monthly rainfall residuals were slightly lower $(p<0.05)$ after the change in landcover $(0.45 \mathrm{~mm} /$ month $)$. For the NSW/VIC locations there was larger decrease in the mean monthly rainfall residual $(p<0.05)$ post change $(1.5 \mathrm{~mm} / \mathrm{month})$.

The observed fraction of significant $Z$ ' scores (at $p<0.1)$ is plotted on the results of the bootstrap distribution (Figure 10). The results support the earlier Z' score results. Only the percentage significant positive Z' scores, indicating a decrease in rainfall for the NSW/VIC region as a result in a decrease in tree cover, falls on the tail of the field significance distribution, while all the others are well within the distribution. This suggests that the percentage of significant positive Z' scores in the NSW/VIC region is least likely due to a unique series of rainfall years, but is most likely due to changes in landcover. In other words, in the NSW/VIC region it is most likely that the change in landcover (decrease in tree cover) caused a decrease in the rainfall. 


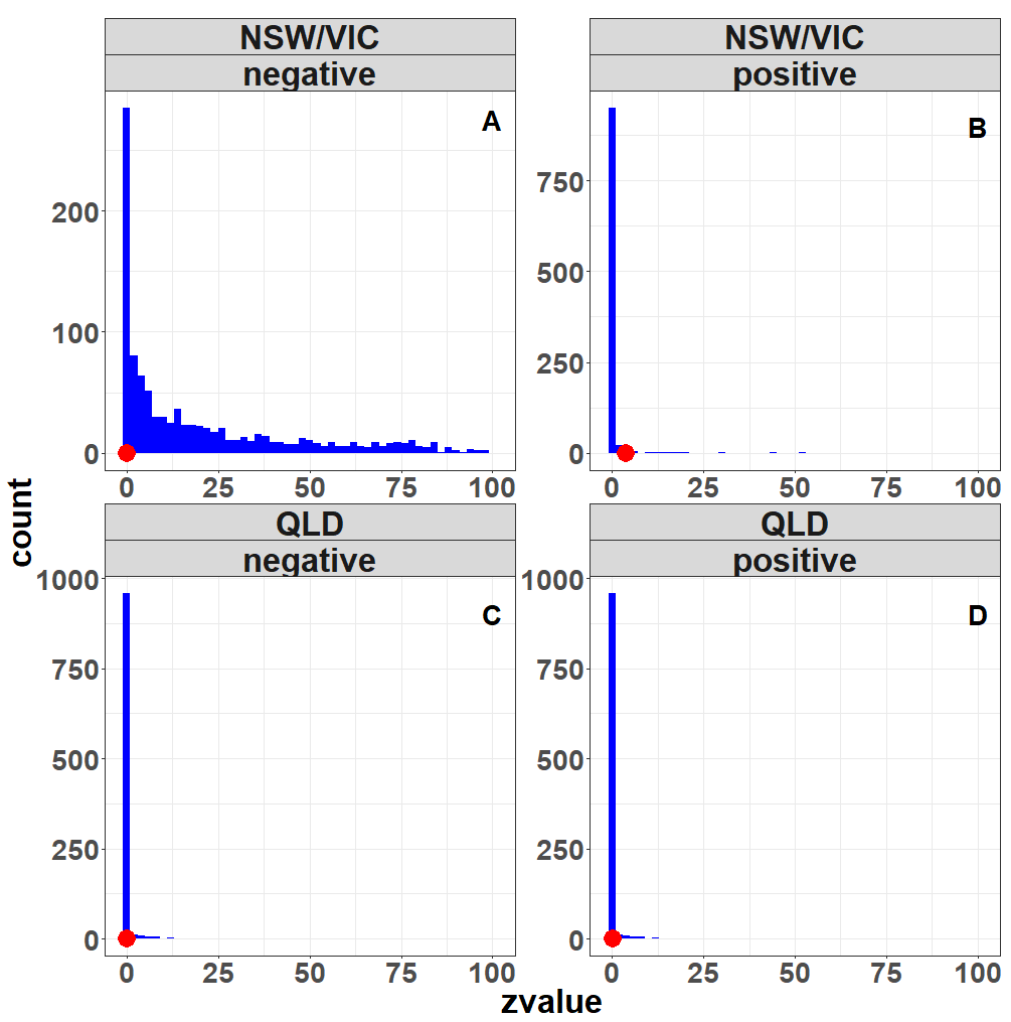

Figure 10. Field significance results showing the distribution of percentage of significant $Z$ ' scores for the resampled series (blue bars), and the precentage significant $Z$ ' scores for the original series of rainfall years (red circle) 
Table 3. Summary table of all tests on the two regions

\begin{tabular}{lll}
\hline Test & Qld & NSW VIC \\
\hline LC variable & Small area of significant pixels in the centre & Large area possibly aligning with bushfire affected area. \\
t-test regression model residuals & Slightly lower mean residual $(p<0.05)$ after change $(0.5 \mathrm{~mm}$ per month $)$ & Lower mean residual $(p<0.05)$ after change $(1.5 \mathrm{~mm}$ per month) \\
Positive score & $0.2 \%$ of pixels at $p<0.1$ & $3.7 \%$ of pixel at $p<0.1$ \\
Field significance \% of scores & Both positive and negative \% within random distribution & Positive \% outside random distribution. \\
\hline
\end{tabular}

\section{DISCUSSION}

Overall the summary table (Table 3) of the results indicates that the effects of land clearing or bushfire on rainfall are consistent across the range of different statistical tests. In all cases, the data for the NSW/VIC region indicates statistical evidence that the reduction in tree cover (the land cover change) resulted in a local decrease in rainfall. In contrast, the data for the QLD region indicates lower statistical evidence that the loss of trees due to land clearing resulted in reduction in the rainfall (Table 3).

Generally, empirical studies on LCC-precipitation interaction are conducted within an area with known land surface intervention (e.g. Otterman et al., 1990; Durieux, Machado \& Laurent, 2003; Negri et al., 2004; Sato, Kimura \& Hasegawa, 2007). However, these locations are rare and difficult to isolate from real landscape change. Modelling studies are abundant (e.g. Chagnon \& Bras, 2005; Wang et al., 2009; Pinto et al., 2009), but these are generally not directly linked to observed data. In this study we tested the effect of land cover change across a broad region, which included locations where changes were known to occur or have occured. The advantage of the current approach is that long time series of land cover data are not required. Furthermore, it does not assume a specific relationship between vegetation cover change and rainfall but allows the data to show this relationship, by applying the analysis to a broader area outside the boundary of the vegetation cover change. This approach is expected to provide a way to reduce the risk of a false positive paradox, by comparing results between areas with and without vegetation cover change.

Overall the results suggest that at least for the NSW/VIC region, a decrease in tree cover causes a decrease in rainfall. However, there are several possible complicating factors in the data that require discussion.

\subsection{Rainfall variability}

Rainfall in Australia is highly variable from year to year, and the time period in this study included a severe drought (Dijk \& Viney, 2013), as well as the drought breaking years 2010 and 2011. The purpose of using the regression model is to remove the year to year and month to month variability in rainfall and therefore strengthen the land cover signal in the residuals. We used the spatially averaged monthly rainfall timeseries for the larger Murray Darling Basin (Figure 1) to remove the general variability. However, overall the model does not explain more than 50\% (QLD) and 30\% (NSW/VIC) of the rainfall variability (Figure 6), and only around 7\% on average is due to the climate drivers (Figure 7). And while this is consistent with the literature e.g. Westra \& Sharma (2010), this means some variation due to external factors could still be left in the residuals. Rainfall is generally considered a stochastic process (e.g. Fowler et al., 2005; Cowpertwait, Salinger \& Mullen, 2009; Burton et al., 2010) and some of the variability could either be a different response to a combination of climate factors (as interactions were not tested in the model), or a non-stationary response to the climate drivers. The severe bushfires in 2003 were also triggered by the extreme drought conditions during the millenium drought (Dijk \& Viney, 2013). Although the effect of the drought on the overall rainfall quantities has been accounted for in part by the model, a further delayed or cumulative effect of the drought could be feeding into the local land-atmosphere interaction. As a result, the rainfall feedback to the vegetation cover change could be weak under the dry conditions between 2001 and 2009, and this could have affected the result.

The fact that no significant long trend was identified, may not disprove a long term trend in rainfall, as overall time period is fairly short (Koutsoyiannis, 2006). Removing the long term trend could mean more pixels in NSW/VIC would indicate a significant step change.

\subsection{Vegetation dynamics}

The second possible effect is the dynamic nature of the vegetation clearing and recovery, especially for the QLD region. Not only does this refer to a change in the total biomass, but this could also include a change in the species composition as a result of the disturbance. 


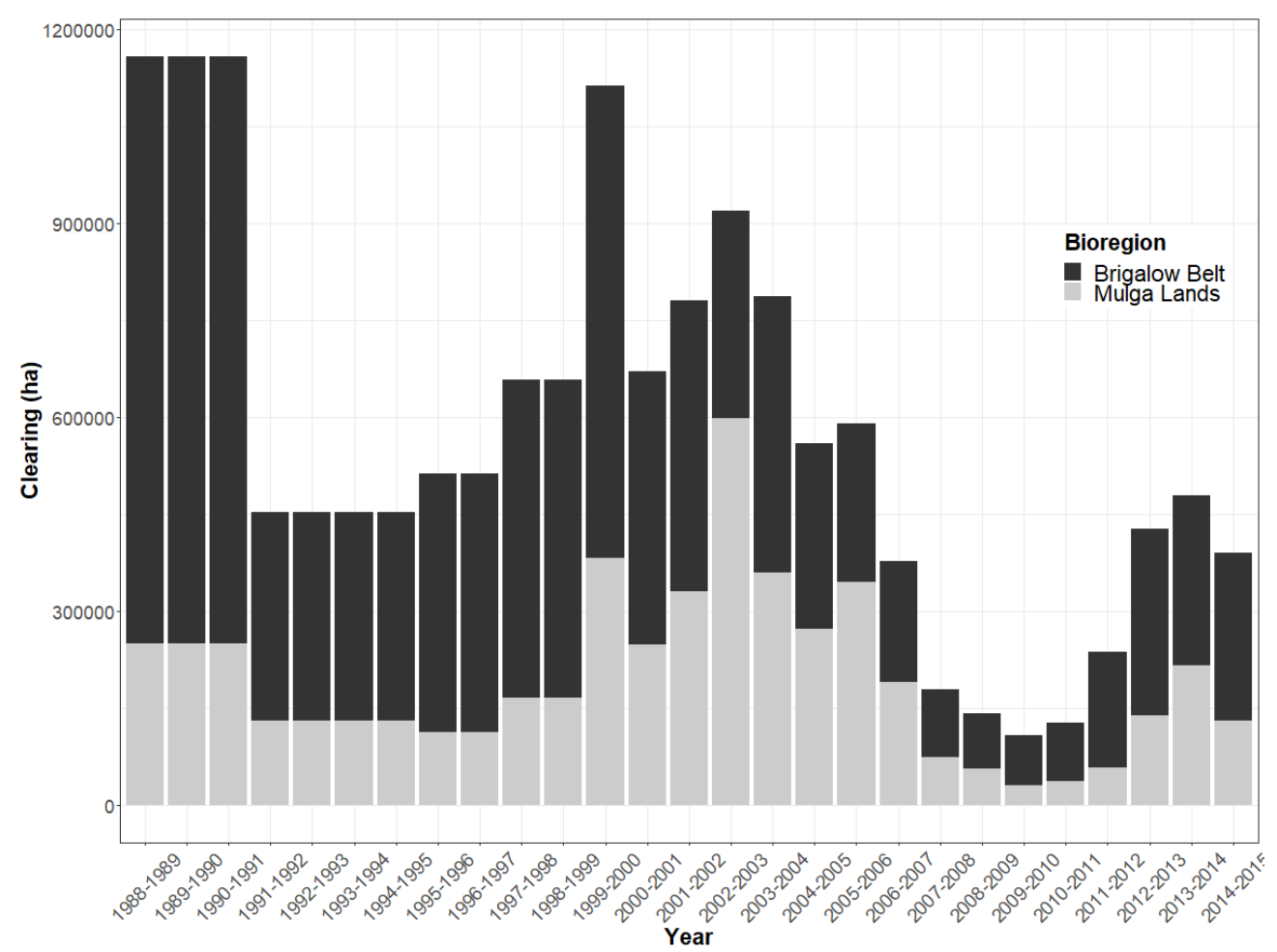

Figure 11. Woody vegetation clearing rate in QLD for the two major bioregions in the study area. The data were obtained from SLATS (2017), and clearly indicate a sharp decrease in the clearing rate after 2005 .

Although land clearing has occurred at a high rate and broad scale in Queensland (Department of Science, Information Technology and Innovation, 2017), the clearing does not have a clear start and end point. QLD has a long history of land clearing. According to the series of SLATS reports on land cover changes in QLD released by the Queensland government, land clearing continued in and around the study region between 1988 - 2008. Major broad scale and high rate clearings occurred in 1999 - 2000 and 2002 2004 (Figure 11). And even though there was a decrease in land clearing post 2005, it is difficult to define a clear cut change in the tree cover in this region.

The specific vegetation class in the Queensland area is also well-known for rapid regrowth and "thickening" in favourable conditions (Gowen \& Bray, 2016), and this could explain the increase in vegetation cover in 2015 in the Qld area (Figure 5). This again, could also be related to a change in the vegetation composition further complicating the analysis. In particular the favourable rainfall years of 2010 and 2011 would have boosted regrowth, increasing evapotranspiration and therefore decreasing the effect of the rainfall change.

The different causes of vegetation cover change in these two regions could lead to different postchange characteristics. The trends in EVI in the QLD region are opposite to the NSW/VIC region, based on the DLCD data. This could also be due to the lower tree density in the QLD region compared to the NSW/VIC region before land surface interventions. In contrast, the significant bushfires (Figure 2) would have drastically reduced the vegetation cover and recovery was very slow in some areas within the NSW/VIC area. The persistent drought in the 2000s (Howden, 2012; Dijk \& Viney, 2013) delayed the regrowth of trees. Conversely, replacing tree cover with pasture and crops in the Qld area might only have a relatively subtle impact on the EVI.

\subsection{Gridded monthly rainfall data}

The rainfall data used in this study is gridded. This data set is robust and consistent over a long time series (from 1900 to current) and has a broad national wide coverage which can provide more information spatially (Jeffrey et al., 2001; Tozer, Kiem \& Verdon-Kidd, 2009). However, high cross correlation between pixels, due to the interpolation method in this data set (Jeffrey et al., 2001), can also introduce 
spatial noise. In the step trend test the cross correlation was accounted for. However, some other methods are also available, which could be used to perform a comparative trial. For example, Narisma et al. (2007) applied a spatial Gaussian filter on a similar data set and used wavelet analysis to detect a step change in rainfall. High quality station data is another option to test whether the observed spatial pattern in the step trend test results was not due to the gridded data itself. Resampling methods, such as bootstrapping and permutation (used in this study) (Wilks, 1997; Kundzewicz \& Robson, 2004; Westra, Alexander \& Zwiers, 2013), can also be used to further assess the strength of the significance of results . While the gridded data set is most useful in regions with sparse rain gauge networks, such as in this study, it can actually reduce information where the rain gauge density is high (Jones, Wang \& Fawcett, 2009). In the NSW/VIC region, the coverage of rainfall stations is more intensive, but they are mainly located in the valleys. As a result, the interpolated data might be a limited representation of the true local rainfall.

\subsection{General approach}

Parametric tests are generally more powerful than nonparametric test in detecting a trend, when the data is normally distributed (Onoz \& Bayazit, 2003; Kundzewicz \& Robson, 2004). As a non-parametric test, the step trend test has the advantage of being distribution free and having no restriction on missing data (Hirsch \& Gilroy, 1985). On the other hand, the disadvantages of non-parametric tests, such as being limited to hypothesis testing and being weaker in power, also hold for the step trend test (Whitley \& Ball, 2002).

Overall, the current study provides a statistical data based approach, building on several lines of evidence to reject the null hypothesis (no step change in rainfall occurs as a result of tree cover loss) at least for the NSW/VIC region. Limited by the available data, the time frame under study had to include a long lasting drought period (Holper, 2011; Dijk \& Viney, 2013). The strong impact of this prolonged drought might have suppressed the land-atmosphere interaction and modified the cause and effect relationship between rainfall and vegetation cover change. This could be one of the reasons that the land cover change effects on the local climate found in other studies (e.g. Görgen et al., 2006; McAlpine et al., 2007) do not appear in the QLD region.

Future research will include additional areas to further test the approach in this study. However, such areas are not easy to find. There are several requirements for a good study area:

1. It needs to be large enough to capture the effect of landuse on rainfall within the area;

2. It needs to have a drastic enough landuse change to be observable above the rainfall variation;

3. It needs to have a long enough climate data time series both prior and post landuse change.

The obvious locations have always been Amazonia and sub-Saharan Africa, where also most of the modelling studies have taken place (Kucharski, Zeng \& Kalnay, 2013; Pitman \& Lorenz, 2016). The problem with the sub-Saharan location is that the land use change is quite long ago and local data is difficult to obtain. The problem with the Amazonian location is that this area is well-known for the feedback and we felt that we could not add much to this work. We propose that it would better to focus on areas affected by bushfires, as we did with the NSW/VIC location. The recent bushfires in California and Colorado could potentially be good locations, but at the moment there is insufficient "post event data". Further work could also focus on identifying an area that has been impacted by land cover change, but does not include a significant drought period.

While the power of the test can be improved with the longer length of the post-intervention period (Hirsch \& Gilroy, 1985), the dynamic nature of vegetation regrowth in this case study also affects this effect. A better approach might be to build a global study that investigates multiple locations where drastic landcover changes have taken place, which would also remove some of the climate variability effects due to the larger sample size.

\section{CONCLUSIONS}

In this study, we present a statistical approach to identify the impact of a change in land cover on local rainfall.The results, based on gridded rainfall data found, that a reduction in vegetation cover is likely to have reduced local rainfall for a large area in NSW/VIC affected by bushfires. However, land clearing in QLD was unlikely to have reduced rainfall over the same time period. 
Drought may have had a pronounced impact on the land surface condition during the study period, such asleading to significant reduction in vegetation cover and extreme events such as bushfires. The lack of rainfall and associated high temperatures may mask the impact on rainfall of a step change in the vegetation cover. Hence, the signal of Land Cover Change feedback on rainfall is probably weaker under such regional dry conditions, as the impact of Land Cover Change on rainfall is mainly through changes in moisture convergence (Görgen et al., 2006; Pitman \& Hesse, 2007).

\section{REFERENCES}

ABARES. 2010. Land use of Australia, Version 4, 2005/2006.

ABC News. 2003. Kosciuszko slow to recover from bushfires.

Australian Bureau of Statistics. 2012. Geography and climate - Australia's climate.

Ben-Gai T, Bitan A, Manes A, Alpert P, Rubin S. 1998. Spatial and temporal changes in rainfall frequency distribution patterns in Israel. Theoretical and Applied Climatology 61:177-190.

BoM. 2012. Australian climate influence.

Bosilovich MG, Chern J-D. 2006. Simulation of water sources and precipitation recycling for the MacKenzie, Mississippi, and Amazon River Basins. Journal of Hydrometeorology 7:312-329.

Buckley T, Turnbull T, Pfautsch S, Gharun M, Adams M. 2012. Differences in water use between mature and post-fire regrowth stands of subalpine eucalyptus delegatensis r. baker. Forest Ecology and Management 270:1-10. DOI: 10.1016/j.foreco.2012.01.008.

Burton A, Fowler H, Blenkinsop S, Kilsby C. 2010. Downscaling transient climate change using a neyman-scott rectangular pulses stochastic rainfall model. Journal of Hydrology 381:18-32.

Chagnon FJF, Bras RL. 2005. Contemporary climate change in the Amazon. Geophysical Research Letters 32.

Chowdhury RK, Beecham S. 2010. Australian rainfall trends and their relation to the Southern Oscillation Index. Hydrological Processes 24:504-514.

Cowpertwait P, Salinger J, Mullen B. 2009. A spatial-temporal stochastic rainfall model for Auckland City: Scenarios for current and future climates. Journal of Hydrology (NZ) 48:95-109.

Deo R, Syktus J, McAlpine C, Wong K. 2009. The simulated impact of land cover change on climate extremes in eastern australia. In: Proceedings of the 18th world imacs congress and modsim09 international congress on modelling and simulation. Modelling; Simulation Society of Australia; New Zealand Inc.; International Association for Mathematics; Computers in Simulation, 2035-2041.

Department of Natural Resources and Mines. 2005. Land cover change in Queensland 2001-2003, incorporating 2001-2002 adn 2002-2003 change periods: A statewide landcover and trees study (SLATS) report. Brisbane: Department of Natural Resources; Mines.

Department of Natural Resources and Water. 2007. Land cover change in Queensland 2004-2005: A statewide landcover and trees study (SLATS) report. Brisbane: Department of Natural Resources; Water.

Department of Science, Information Technology and Innovation. 2017. Land cover change in Queensland 2015-2016: A statewide landcover and trees study (SLATS) report. Brisbane: Department of Science, Information Technology; Innovation.

Dijk B van Albert I. J. M., Viney NR. 2013. The millennium drought in southeast australia (20012009): Natural and human causes and implications for water resources, ecosystems, economy, and society. Water Resources Research 49:1040-1057. DOI: 10.1002/wrcr.20123.

Dirmeyer PA, Brubaker KL, DelSole T. 2009. Import and export of atmospheric water vapor between nations. Journal of Hydrology 365:11-22.

Durieux L, Machado LAT, Laurent H. 2003. The impact of deforestation on cloud cover over the Amazon arc of deforestation. Remote Sensing of Environment 86:132-140.

Eltahir EAB, Bras RL. 1996. Precipitation recycling. Reviews of Geophysics 34:367-378.

Fowler H, Kilsby C, O'connell P, Burton A. 2005. A weather-type conditioned multi-site stochastic rainfall model for the generation of scenarios of climatic variability and change. Journal of Hydrology 308:50-66.

Gaertner MA, Christensen OB, Prego JA, Polcher J, Gallardo C, Castro M. 2001. The impact of deforestation on the hydrological cycle in the western Mediterranean: An ensemble study with two regional climate models. Climate Dynamics 17:857-873.

Gallant AJE, Hennessy KJ, Risbey J. 2007. Trends in rainfall indices for six Australian regions: 1910 
- 2005. Australian Meteorological Magazine 56:223-239.

Gimeno L, Drumond A, Nieto R, Trigo RM, Stohl A. 2010. On the origin of continental precipitation. Geophysical Research Letters 37.

Gowen R, Bray SG. 2016. Bioeconomic modelling of woody regrowth carbon offset options in productive grazing systems. The Rangeland Journal 38:307-317. DOI: https://doi.org/10.1071/RJ15084.

Görgen K, Lynch AH, Marshall AG, Beringer J. 2006. Impact of abrupt land cover changes by savanna fire on northern Australian climate. Journal of Geophysical Research-Atmospheres 111:D19106.

Hastie T, Tibshirani R. 1986. Generalized additive models. Statistical science:297-310.

Hipel K, McLeod A. 1994. Time series modelling of water resources and environmental systems. Elsevier Science Ltd.

Hirsch RM, Gilroy EJ. 1985. Detectability of step trends in the rate of atmospheric deposition of sulfate. JAWRA Journal of the American Water Resources Association 21:773-784.

Holper PN. 2011. Climate change, science information paper: Australian rainfall-past, present and future. Canberra: CSIRO.

Howden S. 2012. It's official: Australia no longer in drought. Brisbane Times.

Hughes L. 2003. Climate change and Australia: Trends, projections and impacts. Austral Ecology 28:423-443.

Jeffrey SJ, Carter JO, Moodie KB, Beswick AR. 2001. Using spatial interpolation to construct a comprehensive archive of australian climate data. Environmental Modelling \& Software 16:309-330.

Jones D, Wang W, Fawcett R. 2009. High-quality spatial climate data-sets for australia. Australian Meteorological and Oceanographic Journal 58:233-248.

Junkermann W, Hacker J, Lyons T, Nair U. 2009. Land use change suppresses precipitation. Atmospheric Chemistry and Physics 9:6531-6539.

Kamruzzaman M, Beecham S, Metcalfe AV. 2011. Non-stationarity in rainfall and temperature in the Murray Darling Basin. Hydrological Processes 25:1659-1675.

Koutsoyiannis D. 2006. Nonstationarity versus scaling in hydrology. Journal of Hydrology 324:239_ 254.

Kucharski F, Zeng N, Kalnay E. 2013. A further assessment of vegetation feedback on decadal Sahel rainfall variability. Climate dynamics 40:1453-1466.

Kuczera G. 1987. Prediction of water yield reductions following a bushfire in ash-mixed species eucalypt forest. Journal of Hydrology 94:215-236. DOI: https://10.1016/0022-1694(87)90054-0.

Kundzewicz Z, Robson A. 2004. Change detection in hydrological records-a review of the methodology/revue méthodologique de la détection de changements dans les chroniques hydrologiques. Hydrological sciences journal 49.

Lymburner L, Tan P, Mueller N, Thackway R, Lewis A, Thankappan M, Randall L, Islam A, Senarath U. 2010. 250 metre Dynamic Land Cover Dataset.

Ma HY, Mechoso CR, Xue Y, Xiao H, Wu CM, Li JL, De Sales F. 2011. Impact of land surface processes on the South American warm season climate. Climate Dynamics 37:187-203.

MacDonald GM, Case RA. 2005. Variations in the pacific decadal oscillation over the past millennium. Geophysical Research Letters 32:L08703.

McAlpine CA, Syktus J, Deo RC, Lawrence PJ, McGowan HA, Watterson IG, Phinn SR. 2007. Modeling the impact of historical land cover change on Australia's regional climate. Geophysical Research Letters 34.

Mei R, Wang GL. 2010. Rain follows logging in the Amazon? Results from CAM3-CLM3. Climate Dynamics 34:983-996.

Meneghini B, Simmonds I, Smith IN. 2007. Association between Australian rainfall and the Southern Annular Mode. International Journal of Climatology 27:109-121.

Murphy BF, Timbal B. 2008. A review of recent climate variability and climate change in southeastern Australia. International Journal of Climatology 28:859-879.

Nair US, Wu Y, Kala J, Lyons TJ, Pielke S R. A., Hacker JM. 2011. The role of land use change on the development and evolution of the west coast trough, convective clouds, and precipitation in southwest Australia. Journal of Geophysical Research-Atmospheres 116:D07103.

Narisma G, Foley J, Licker R, Ramankutty N. 2007. Abrupt changes in rainfall during the twentieth century. Geophysical Research Letters 34:L06710.

Negri AJ, Adler RF, Xu LM, Surratt J. 2004. The impact of Amazonian deforestation on dry season 
rainfall. Journal of Climate 17:1306-1319.

Nicholls N. 2006. Detecting and attributing Australian climate change: A review. Australian Meteorological Magazine 55:199-211.

Oleson KW, Bonan GB, Levis S, Vertenstein M. 2004. Effects of land use change on North American climate: Impact of surface datasets and model biogeophysics. Climate Dynamics 23:117-132.

Onoz B, Bayazit M. 2003. The power of statistical tests for trend detection. Turkish Journal of Engineering and Environmental Sciences 27:247-251.

Otterman J, Manes A, Rubin S, Alpert P, Starr D. 1990. An increase of early rains in Southern Israel following land-use change? Boundary-Layer Meteorology 53:333-351.

Pinto E, Shin Y, Cowling SA, Jones CD. 2009. Past, present and future vegetation-cloud feedbacks in the Amazon Basin. Climate Dynamics 32:741-751.

Pitman AJ, Hesse PP. 2007. The significance of large-scale land cover change on the Australian palaeomonsoon. Quaternary Science Reviews 26:189-200.

Pitman AJ, Lorenz R. 2016. Scale dependence of the simulated impact of Amazonian deforestation on regional climate. Environmental Research Letters 11:094025. DOI: 10.1088/1748-9326/11/9/094025.

Pitman AJ, Narisma GT, Pielke RA, Holbrook NJ. 2004. Impact of land cover change on the climate of southwest Western Australia. Journal of Geophysical Research-Atmospheres 109.

R Core Team, 2018. R: A Language and Environment for Statistical Computing. Vienna, Austria: R Foundation for Statistical Computing.

Risbey JS, Pook MJ, McIntosh PC, Wheeler MC, Hendon HH. 2009. On the remote drivers of rainfall variability in Australia. Monthly Weather Review 137:3233-3253.

Roy DP, Boschetti L, Justice CO, Ju J. 2008. The collection 5 modis burned area product-Global evaluation by comparison with the modis active fire product. Remote Sensing of Environment 112:3690 3707.

Roy D, Jin Y, Lewis P, Justice C. 2005. Prototyping a global algorithm for systematic fire-affected area mapping using modis time series data. Remote sensing of environment 97:137-162.

Roy D, Lewis P, Justice C. 2002. Burned area mapping using multi-temporal moderate spatial resolution data-A bi-directional reflectance model-based expectation approach. Remote Sensing of Environment 83:263-286.

Saha SK, Dirmeyer PA, Chase TN. 2016. Investigating the impact of land-use land-cover change on Indian summer monsoon daily rainfall and temperature during 1951-2005 using a regional climate model. Hydrology and Earth System Sciences 20:1765.

Saji N, Goswami B, Vinayachandran P, Yamagata T. 1999. A dipole mode in the tropical Indian Ocean. Nature 401:360-363.

Sato T, Kimura F, Hasegawa AS. 2007. Vegetation and topographic control of cloud activity over arid/semiarid Asia. Journal of Geophysical Research-Atmospheres 112.

Schepen A, Wang QJ, Robertson D. 2012. Evidence for using lagged climate indices to forecast australian seasonal rainfall. Journal of Climate 25:1230-1246.

Semazzi FHM, Song Y. 2001. A GCM study of climate change induced by deforestation in Africa. Climate Research 17:169-182.

Smith IN, Timbal B. 2012. Links between tropical indices and southern Australian rainfall. International Journal of Climatology 32:33-40.

Speer M, Leslie L, Fierro A. 2011. Australian east coast rainfall decline related to large scale climate drivers. Climate Dynamics 36:1419-1429.

The State Government of Victoria. 2011. Bushfire history.

Timbal B, Arblaster J. 2006. Land cover change as an additional forcing to explain the rainfall decline in the south west of Australia. Geophysical Research Letters 33:L07717.

Townshend J, Carroll M, Dimiceli C, Sohlberg R, Hansen M, DeFries R. 2011. Vegetation continuous fields MOD44B, 2001 Percent tree cover, Collection 5.

Tozer CR, Kiem AS, Verdon-Kidd DC. 2009. On the uncertainties associated with using gridded rainfall data as a proxy for observed. In: Anderssen R, Braddock R, Newham L eds. 18th world imacs congress and modsim09 international congress on modelling and simulation. 3886-3892.

Tozer CR, Kiem AS, Verdon-Kidd DC. 2012. On the uncertainties associated with using gridded rainfall data as a proxy for observed. Hydrol. Earth Syst. Sci. 16:1481-1499. DOI: 10.5194/hess-16- 
1481-2012.

Trenberth KE. 1999. Atmospheric moisture recycling: Role of advection and local evaporation. Journal of Climate 12:1368-1381.

Verdon DC, Wyatt AM, Kiem AS, Franks SW. 2004. Multidecadal variability of rainfall and streamflow: Eastern Australia. Water Resources Research 40:W10201.

Wang J, Chagnon F, Williams E, Betts A, Renno N, Machado L, Bisht G, Knox R, Bras R. 2009. Impact of deforestation in the Amazon basin on cloud climatology. Proceedings of the National Academy of Sciences of the United States of America 106:3670.

Westra S, Sharma A. 2010. An upper limit to seasonal rainfall predictability? Journal of Climate 23:3332-3351.

Westra S, Alexander LV, Zwiers FW. 2013. Global increasing trends in annual maximum daily precipitation. Journal of Climate 26:3904-3918.

Whitley E, Ball J. 2002. Statistics review 6: Nonparametric methods. Critical Care, London 6:509_ 513.

Wilks D. 1997. Resampling hypothesis tests for autocorrelated fields. Journal of Climate 10:65-82.

Wilks DS. 2006. On "field significance" and the false discovery rate. Journal of Applied Meteorology and Climatology 45:1181-1189.

Wood SN. 2011. Fast stable restricted maximum likelihood and marginal likelihood estimation of semiparametric generalized linear models. Journal of the Royal Statistical Society (B) 73:3-36.

Zanchettin D, Franks SW, Traverso P, Tomasino M. 2008. On enso impacts on european wintertime rainfalls and their modulation by the nao and the pacific multi-decadal variability described through the pdo index. International Journal of Climatology 28:995-1006.

Zeng XM, Wu ZH, Song S, Xiong SY, Zheng YQ, Zhou ZG, Liu HQ. 2012. Effects of land surface schemes on the simulation of a heavy rainfall event by WRF. Chinese Journal of Geophysics-Chinese Edition 55:16-28. 